\title{
Converged Delivery and Beyond....
}

\author{
William Smart and George Coles \\ Southern Cross Business School, Southern Cross University, \\ Locked Bag 4 Coolangatta, QLD 4225, Australia \\ E-mail: bill.smart@scu.edu.au
}

\begin{abstract}
This paper focuses on the use of technology, assessment strategy, rubrics and a proactive approach to enhance student engagement. This strategy, encourages students to join in discussions with their peers (regardless of locations), in an attempt to break the sense of "isolation" suffered by distance learning students. This approach meets the definition of converged delivery in that it allows all students, regardless of mode of enrolment, the flexibility to study in a manner that balances with their other life commitments. The paper presents a case study of an undergraduate information technology unit, which has undergone continuous improvement over a five-year period.
\end{abstract}

Keywords: Proactive approach, converged delivery, rubrics, distance education, student support

\section{Introduction}

The case study of the Southern Cross Business School's unit Web Development I is presented here to demonstrate that the design of the unit, appropriate use of converged delivery technologies, assessment strategies including design, rubrics and a proactive approach can improve the learning outcomes of students enrolled in the unit regardless of the mode of enrolment.

The paper first examines the unit design and makeup of the student cohort during the period 2009-2013. Then the converged delivery technologies currently in use or adopted for use in the same time span are detailed. Assessment strategy and in particular the changes to the design and grading of the units assessments are explored next. Finally, the results of the previously existing and introduced teaching practises are scrutinized in relation to student perceptions and learning outcomes in the unit.

\section{The Unit}

The Web Development I unit is a first year Information Technology (IT) unit offered by the Southern Cross Business School of Southern Cross University.

The unit objectives state: "After successful completion of this unit, students will be able to:
- describe the essential processes of web development

- interpret and apply a web mark-up language

- apply written communication skills to a website

- recognise and implement ethical, legal and societal issues related to web development

- demonstrate the ability to build efficient and usable websites"

The unit was designed using constructive alignment, where all parts of the teaching; the teaching mode, climate, curriculum and assessment are aligned in a student-centred manner ${ }^{1,2}$. The structure used to cover the content of this subject is the problem-centred structure as described by Rowntree ${ }^{3}$.

Each topic in the subject provides the student with a skill-set, and then engages the student in deep-learning ${ }^{2}$ with the content through a series of problem-based ${ }^{3,4}$ self-assessed activities. This problem solving approach is then taken to a higher level by tasks required in the formally assessable activities. Following is a quote from Toohey describes the concept of the topic structures and the entire subject as a whole:

"So developers of problem-based or project-based courses usually select or develop the problems or projects for students within a clearly defined structured 
framework that will help them consistently develop their abilities. The most likely to be used are those provided by a performance analysis of the discipline or profession such as would be done in developing a competency-based course of framework based on the logic of the subject material ${ }^{4}$."

All the student support materials for the subject; PowerPoint presentations, study guide, sample HTML pages, JavaScript programs, WWW links and additional readings are available on the units on-line Blackboard site for all cohorts of students. This material was written to be flexible, as it is delivered in multiple modes (oncampus, distance and overseas). Care was taken in authoring the student support material to comply with suggestions given by Rowntree. Some of these are:

“... clearly stated objectives, user-friendly 'You and I' style of writing, short manageable chunks of learning, plenty of helpful examples and illustrations used where they are better than words ${ }^{4}$."

The major assessment for this unit clearly addresses the objectives of the unit; students are required to design and implement a personal electronic portfolio live on the World Wide Web. The website requires detailed knowledge of several technologies, in particular, File Transfer Protocol (FTP), HyperText Markup Language (HTML), Cascading StyleSheets (CSS) and to a lesser degree JavaScript.

\section{The Student Cohort}

This is a first year core unit in the following IT degrees: Associate Degree of Information Technology, Bachelor of Information Technology, Bachelor of Applied Computing and the Graduate Diploma in Information Technology. In addition to the IT degrees this unit is a required unit for an IT major in the Bachelor of Business degree (Information Systems or Digital Media).

However, this unit is also available as a university wide elective. It seems (as expected) that students from many fields of study are interested in learning how to develop websites. Table 1 displays the students categorised by degree undertaking the unit over the last five years. As a result of this mix of students, basic IT skills required in this unit cannot be assumed to exist at the same level across the student cohort. All materials designed for and presented within the unit therefore need to assume no pre-existing IT skills in the cohort.

\section{Delivery Modes}

The Southern Cross Business School is committed to equitable learning opportunities for all students regardless of enrolment mode. Consequently, each mode of delivery has more commonalities than differences.

However, it should be noted that each of the modes of delivery is differs to some degree. This is particularly the case with the university's educational partners in

Table 1. Students by Degree (2009-2013)

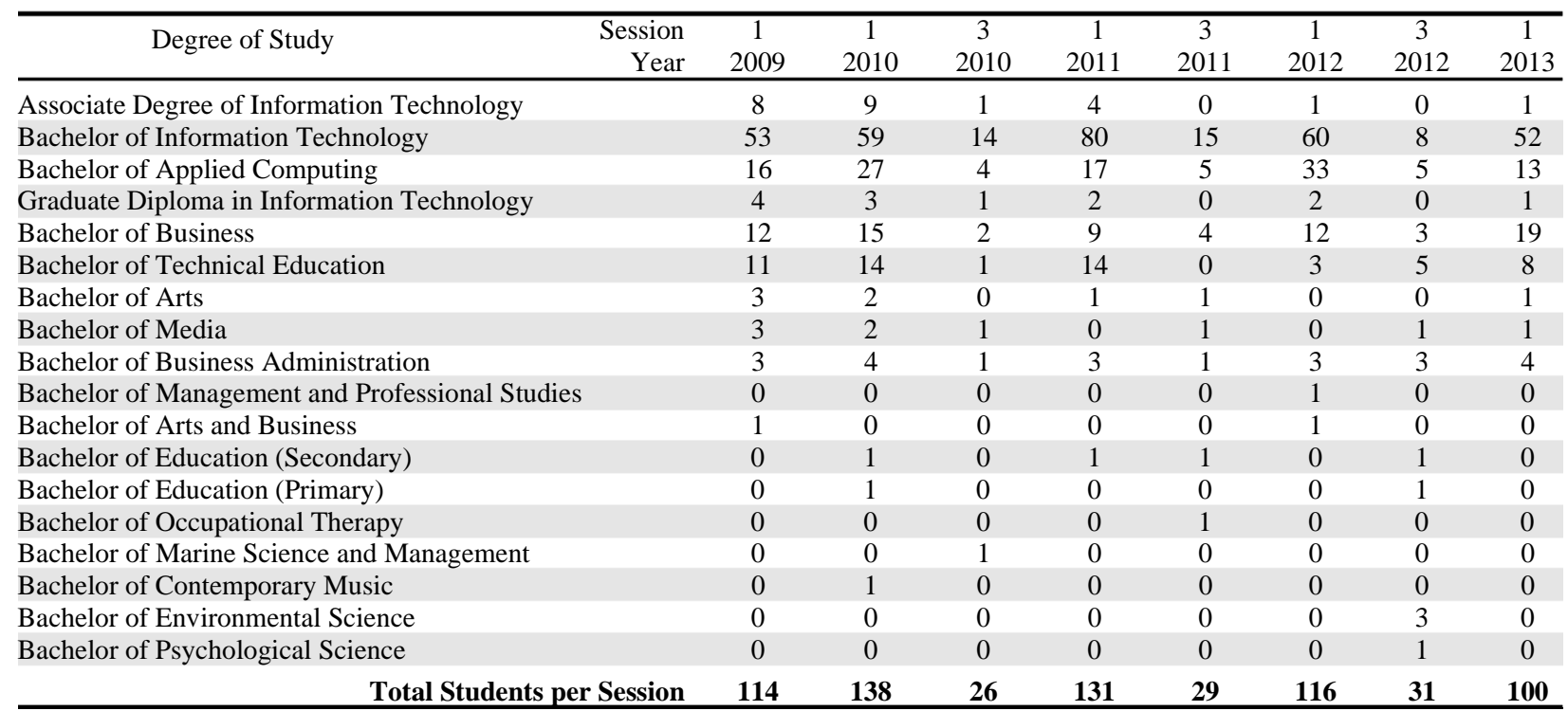

Note: Southern Cross University instituted a three session year in 2010 
Table 2. Students by Mode of Delivery (2009-2013)

\begin{tabular}{|c|c|c|c|c|c|c|c|c|}
\hline $\begin{array}{r}\text { Session } \\
\text { Year } \\
\end{array}$ & $\begin{array}{c}1 \\
2009 \\
\end{array}$ & $\begin{array}{c}1 \\
2010 \\
\end{array}$ & $\begin{array}{c}3 \\
2010 \\
\end{array}$ & $\begin{array}{c}1 \\
2011 \\
\end{array}$ & $\begin{array}{c}3 \\
2011 \\
\end{array}$ & $\begin{array}{c}1 \\
2012 \\
\end{array}$ & $\begin{array}{c}3 \\
2012 \\
\end{array}$ & $\begin{array}{c}1 \\
2013 \\
\end{array}$ \\
\hline Internal Coffs Harbour & 34 & 48 & 0 & 42 & 0 & 24 & 0 & 28 \\
\hline Internal Gold Coast & - & - & - & - & - & 11 & 0 & 26 \\
\hline Internal Sydney & - & - & - & - & - & - & - & 2 \\
\hline External & 31 & 46 & 26 & 47 & 29 & 32 & 27 & 39 \\
\hline Domestic Educational Partnership & 28 & 35 & 0 & 34 & 0 & 32 & 4 & 0 \\
\hline Over/Seas Educational Partnership(s) & 21 & 9 & 0 & 8 & 0 & 17 & 0 & 5 \\
\hline Total Students per Session & 114 & 138 & 26 & 131 & 29 & 116 & 31 & 100 \\
\hline
\end{tabular}

Notes: All educational partnerships (International/Domestic) in IT are in teach-out mode (cessation 2014) bar Papua New Guinea. Gold Coast campus of Southern Cross University was introduced session 1, 2012 (opened previously). Sydney campus of Southern Cross University was introduced in session 1, 2013 (launched session 2, 2013).

delivery of the unit (overseas and domestic). Table 2 identifies the same student cohort as Table 1, but via location rather than degree.

Following is a brief discussion highlighting the similarity and differences of delivery mechanisms for each of these modes.

- Lectures are delivered to all student cohorts via Collaborate each of the 12 weeks of session. These lectures are recorded and made available in streaming and downloadable mode for the entire session.

- All unit materials (assessments, study guide, PowerPoint presentations, web links, and activities) are completely hosted on-line on the units Blackboard site.

- All assessments are submitted and feedback is returned to students via the on-line grade book facility provided by the Blackboard environment.

\subsection{Internal Students}

In addition to the on-line materials and the on-line lecture learning support for internal students regardless of campus is accomplished by offering a 2-hour tutorial for each teaching week of session. In addition, the unit lecturer/tutor offers at minimum a 3-hour consultation time per week.

\subsection{External Students}

Whereas the typical internal student has at minimum access to a tutor for a period of 2 hours per week, the external student has much less learning support offered to them. The typical support for an external student in the school's workload model is two hours per session comprised of 1.5 hours of marking time and .5 hours of support time per student in each session. Typically, the tutor's funded time is spent on responding to questions raised by emails, and checking the discussion forums. This can be considered a reactive model; when the student raises a problem it is handled by the lecturer/tutor, if no problem is raised little or no contact between tutor/lecturer occurs.

Distance education students feel isolated ${ }^{6,7,8,9}$ from their institution and peers, hence developing a sense of belonging in the institution/subject can be difficult. Literature suggests that a sense of belonging will increase student's likelihood of continuing and succeeding in their studies ${ }^{6,8,9,10,11}$.

In 2010/2011 as part of the Converged Delivery project at Southern Cross University, in an attempt to reduce this "isolation" the opportunity for external students to attend a four hour workshop was created. Whereas all students whom attended the workshop found it to be an excellent learning resource, only a small number of students availed themselves to the opportunity. This result meant that a different way to address the "isolation" and "belonging" problem would need to be found.

\subsection{Session three offering}

Southern Cross University started using a three session calendar in 2010. The only enrolment mode in this session for IT units is external. This is simply a resources issue, as there are not enough full time IT academics to run the unit in internal mode. This means that students in this session have the pre-recorded (in all formats previously discussed) lectures from session 1 . This has proved problematic as the students had no interactive contact with tutors and feedback from students highlighted this. In 2012 this failing was recognised and a policy of introducing four workshops (via Collaborate) during the session was trialled. This improved the students' satisfaction with the unit offering in session 3 . 


\subsection{Partner organisations}

Each of the university's educational partnerships is slightly different; however most provide a local academic to lecture/tutor the students in a face-to-face mode. Access to the unit's material is available to the local lecturer via the units Blackboard site and in almost all cases students have their own access to the unit's Blackboard site (lack of reliable Internet in Papua New Guinea is the exception to this rule) .

Additionally, submission of assessment items is accomplished via the grade book in the unit's Blackboard site. This allows for speedy moderation of partners marking by the unit assessor, as access to all students' assessments and local tutor marking is available upon completion. The university demands at minimum $10 \%$ of all assessment items be moderated. Use of the Blackboard grade book allows moderation of each assessment item in as close to real time as possible, in some cases detecting and rectifying errors prior to the marking being completed. Again the education partner in Papua New Guinea is the exception to this rule due to Internet issues. Student assessment moderation is accomplished via email instead (within a two week period).

\section{Technologies for Converged Delivery}

Converged delivery is difficult to define as many other terms in educational literature describe the concept or parts of the concept for example; Blended learning $^{12,13,14}$, Blended online learning ${ }^{15}$, Converged learning environment ${ }^{16,17}$, Convergence ${ }^{18}$, Distributed learning $^{19}$, E-learning ${ }^{20}$, Flexible learning ${ }^{20,21}$ and many others. Southern Cross University's vision for Converged Delivery was first conceptualised in 2007 as:

“... every Southern Cross University student should have a range of pedagogically sound study options to best suit their learning preferences and their work and life demands. This vision would see all students, whether geographically in close proximity to a campus or not, provided with equitable learning opportunities through a single enrolment mode $e^{22}$."

In 2010/2011, the university, using an action based research framework, conducted the 'Converged Delivery Project' this unit was selected as one of the 39 pilot units to be redeveloped within this framework ${ }^{23}$. Since this point in time, additional learning resources have been added to the unit to compliment the work completed. Following is a description of the technologies currently used to facilitate delivery of the unit.

\subsection{Blackboard}

All written unit materials are available on-line for download from the units Black Board site. This material includes:

- Unit Announcements

- Unit Information Guide (including unit statement)

- Student feedback from the previous year's students (includes changes to unit materials/content in relation to feedback)

- Unit Study Guide (as a single document)

- PowerPoint slides for each topic,

- Solutions to the activities for each weeks topics in the study guide

- Unit Software - Web links to software recommended for the unit. All software recommended for the unit is freeware, it includes: FileZilla (including setup guide for the school's web server), 7-Zip, C-map, Notepad++, Gimp and PIXresizer)

- All assessments, the assessment marking guides (spreadsheet format), digital upload facilities for the student's assessment and special consideration form for assessment extensions (if required)

- Additional assessment resources including:

$>$ Sample design documents,

$>$ Design templates

$>$ Web links

$>$ U-Tube videos

$>$ Enovation workshop - written as an intense 4 hour workshop, it details the design and construction "step-by-step" of a small business website

$>$ Exam preparation material

All material on the Web Development I Blackboard site is made available to students at least one week prior to the start of the session. By designing the material to be comprehensive and releasing it early to the students, it clarifies the goals of the unit for the student.

\subsection{Asynchronous discussion board}

The use of the asynchronous discussion forums (available within the Blackboard site) is strongly encouraged and supported in the unit. Students have 
consistently used the discussion board over the last four years. The discussion forum provides two distinct advantages; it allows students to assist each other and provides an additional method of contact between the student and the tutor/lecturer. Additionally, any comments/answers provided to a student via the forum is available to all students, thus reducing repetition (via email). In this way, the discussion board assists in building a sense of community in the student cohort (regardless of mode of delivery).

\subsection{Collaborate}

In 2013, twelve 1-1.5 hour Collaborate lectures were presented in this unit. These were well attended by students, with a maximum of thirty three (33) students attending at any one time. Whereas this is a low number, when compared with the total number of students in the unit (101) it provided interactive questioning between the lecturer and the students attending the lectures (and thereby to those reviewing the recording).

All Collaborate lectures are recorded for students and are available for playback on the Black Board site. However, using the standard recording has drawbacks, as it requires large bandwidth (as it is saved as a .mp4) and/or requires an active connection to the Internet (streaming view). To further increase flexibly/equity for the students each lecture was also converted to .jar file (full audio/visual - typically PowerPoint with interactive audio - approximately 25Meg/hour) and as an .mp3 (audio only) for download.

Students find the recorded (on demand) Collaborate lectures particularly important to their learning; this was evidenced by the results of the converged delivery project 2010/2011 questionnaire where $91 \%$ of students identified recorded Collaborate sessions as useful for their learning ${ }^{23}$.

\subsection{Camtasia}

As previously stated, Web Development I attracts students from many different degrees throughout the university. Because of this mix of students, basic skills expected in IT students cannot be assumed to exist within the student cohort. In 2011 as part of the converged delivery project a series of additional resources (Camtasia videos) were designed and created to assist students in developing these skills regardless of their discipline or their mode of study. The Camtasia files were created in multiple video formats, Windows Movie Format (.wmf), Quicktime (.mov) and .mp4 (ipod, iphone, android etc.) to assist students regardless of the platform they were viewing the files with (Windows, Mac, mobile device). The specific skill videos designed for non IT students were:

- Creating a Zip file Using 7zip

- FTP (File Transfer Protocol) to upload to the Schools server

- Creating a basic HTML file

Several additional Camtasia video files have been recorded since the Converged Delivery Project, currently the unit has an additional six files dealing specifically with the unit content. Each of the Camtasia files demonstrates to students the practical skills they need in developing/authoring a website. These are:

- Validating a HTML file (2011)

- Using CSS Part I, II (2011)

- Using CSS Part III and IV (2012)

- Dealing with Images (2012)

- Basic JavaScript form validation Part I, II (2013)

The Camtasia files range between 5 and 25 minutes in duration, depending on the complexity of the skill being demonstrated. The Camtasias developed for this unit have been an extremely useful addition to the resources provided for students' learning, many comments on their usefulness have been received directly from the students themselves, for example in 2012 one student wrote:

"By far and away, the Camtasias were the most productive learning tools I've ever used. If a picture paints a thousand words, imagine how many words a Camtasia paints.”

\subsection{Hosting server}

As stated previously the major assessment for this unit is a personal electronic portfolio live on the World Wide Web. All students (regardless of mode Internal, External and Over/Seas) are required to place their portfolio on the same hosting site. In order to facilitate this, the School maintains their own Linux based server. This again provides equity across the board for all students.

\section{Assessment Strategy}

The first seven topics (12 topics total) within the subject had a formal assessment activity associated with the problem-based $^{4,5}$ self-assessed activities. Each of these 
seven continuous topic assessments addressed the core skills (site design, HTML, CSS, FTP, validation) required by the student to complete the unit's major assessment, the design and implementation of a web based personal electronic portfolio.

To clarify the requirements of the formal assessment, the students are provided a marking guideline (an excel spreadsheet) containing exactly what the marker will be looking for in each of the continuous assessments. The first assessment (containing the continuous assessments) is then uploaded (as a zip file) by the student to the units Blackboard site in week eight of semester for formal marking and feedback. The feedback from this assessment directly contributes to the learning of the students by clarifying any errors, or misunderstanding in these core skills, and preparing them for success in the major assessment.

Additional skills explored in several of the remaining topics also contribute to the major assessment (additional design skills, HTML forms and JavaScript) but are dependent upon the students' mastery of the core skills in Assessment 1.

The unit's major assessment a personal portfolio is uploaded both as a zip file (including full design documentation) to the Blackboard site and as a live website (sans design documentation) on the Schools hosting server (via FTP). Again, students are provided with a spreadsheet detailing what markers will be specifically looking for, in their design documents, coding and on the hosting server.

The final assessment in the unit is an exam, worth $40 \%$ of the students mark. This is a formal invigilated exam. As Web Development I is a designated first year unit, under the First Year @SCU policy (introduced in 2009), all students are allowed to re-sit this exam if they fail, provided they have achieved a passing mark in the total of all other assessment items in the unit.

\subsection{Assessment restructure}

In 2012, in an effort to improve outcomes for both students and staff associated with the unit and acting on the results of the university's "Excellence in

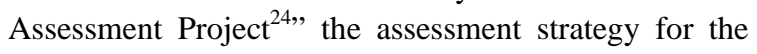
unit was modified from two assessments to three.

This was undertaken to address problems that had become apparent with the first assessment containing the seven continuous topic assessments mentioned earlier. These problems were:

- Students were not engaging with the unit materials as desired. Although each of the first seven topics had a formal assessment associated with it that should be completed each week of session, many students were not attempting to complete them until the assessment itself was due. As a result, students became overwhelmed by the amount of work to be accomplished to complete the assessment.

- Each skill assessed in the first seven topics built upon the previous, therefore each error, misunderstanding or skill not mastered by students compounded the errors in the assessments that followed.

- Website design elements included as part of the continuous topic assessments were problematic for students as they regarded these as pointless additional work in relation to the single or couple of web pages each continuous assessment required.

- There was no formal need to upload material to the hosting web server, although it was recommended to do so in most of the continuous topic assessments. Therefore many students had not attempted this prior to the major assessments due date. This caused additional stress to the student if problems were encountered.

- For staff undertaking marking, each student assessment was taking far more time to mark than was budgeted. This was the result of all of the aforementioned problems, as each caused the amount of feedback required to assist the student to increase. This in addition to the fact that marking seven individual assessments with multiple criteria is quite arduous and time consuming.

To address these issues the seven continuous topic assessments that had previous form the basis of the first formal assessment was divided into two assessments rather than one. The major assessment as detailed previously then became the third assessment.

The first assessment then became comprised of the first three of the seven continuous topic assessments and due in week four of session. This meant that students engaged with the material earlier and received feedback earlier, thus reducing the compounded errors in the four continuous topic assessments that follow. Additionally, 
the third continuous topic assessment was modified, to require students to upload the web pages produced to the hosting server. This allows students to prepare much earlier and helps to identify any problems prior to the major assessment's due date.

Assessment two became the four remaining continuous topic assessments and due in week eight. This assessment, rather than have the student include design documentation associated with any of the individual continuous assessments, places the focus on the major assessment. This allows the students to see the purpose of the design documentation in relation to a complete website. In this way refocusing the design documentation upon the major assessment, allows both the student and staff to see if the student's plan for the site is on-track. The feedback provided then allows each student a chance to improve the outcome of the final major assessment's documentation as well as the site itself.

\subsection{Rubrics}

Research into the use of rubrics has demonstrated that usage can clarify assessment requirements, provide consistency in grading student assessments, convey effective feedback, save grading time and promote student learning ${ }^{26,27,28,29}$.

To reduce the time required for marking of the assignments and to maximize the feedback to students in this unit, rubrics were developed for each of the three formal assessments (using excel spreadsheets). Support for this type of marking method is found in the university's recommendations of the final report of the Excellence in Assessment Project Final Report ${ }^{24}$. However, it should be noted that:

- Students are still provided marking guides detailing how the assessments will be marked.

- The rubrics used for marking assessment one and two (excel spreadsheets extensively using macros) rather than being used to score the student's work is designed to maximise feedback to the student. Where an error is detected the student is directed to the learning resource (Camtasia video, lecture, sample document, activity, study guide etc.) where the specific skill/concept is detailed. The rubrics were developed using excel spreadsheets with macros, which allowed for maximum flexibility in providing rich feedback to the students.

- The rubric designed for marking the major assessment was specifically designed to score each criterion (17 criteria of differing values were used for the assignment) on a scale of 1 to 10 . Minimal feedback is provided to students for this assignment (unless requested by the student) as it is due a week prior to the exam week and it is preferable to provide students with the results of all their assignments prior to the exam. This rubric was also developed as a spreadsheet using several macros.

\subsection{Proactive approach}

Taking a proactive approach to make contact with distance education students has been shown to improve learning outcomes of students in past research ${ }^{25}$. This proactive approach is used in relation to all domestic students regardless of enrolment mode in this unit. This is accomplished by:

- Monitoring the students' on line access - if it drops off for a two-week period the student is emailed and asked... "if there is any problem?"

- If an assessment is not submitted by the due date, the student is emailed seeking information as to why this is the case and what assistance may be needed.

- If an assessment has still not been submitted after a period of 5 days the student is phoned seeking an explanation.

This proactive approach was not been extended to the educational partner's cohorts due to differing requirements/procedures at each location.

\section{Evidence of Improvement}

Many different improvements to the usage of learning technologies, introduction of learning resources, and assessment design/strategy have been discussed in this paper. Trying to itemise each improvement and demonstrate how it has improved student learning outcomes or student perceptions is problematic, as the unit has been undergoing continuous improvement over the last four years. Instead, perhaps it is better to examine the results as a synergy of all of the introduced improvements. 


\subsection{Student outcomes}

Many of the improvements to the unit have been introduced in the period 2011-2013. This includes:

- Teaching Technologies - including Collaborate, Discussion Forums, the units own web server, Camtasia video skills lessons and the units Blackboard site.

- Assessment scaffolding, assessment restructuring and the introduction of rubrics designed to direct students to the learning resource were any shortcomings in their assessment tasks can be rectified.

- Also discussed was the proactive approach to teaching used in the unit.

The synergy of all of the changes introduced to the unit is an improvement in student outcomes in the Web Development I unit. Table 3 presents the student outcomes for all sessions 2011-2013 Student results change session to session and year to year with differences in the student cohort itself. However, as can clearly be seen there is a trend towards higher marks over the five sessions shown. Although it must be noted that even with all of the improvements to the unit the failure rate has still remained high at approximately $20 \%$, this is still a cause for concern.

\subsection{Student perceptions}

Each session the university conducts a unit feedback survey for each unit offered. This is where students can voice their opinion and perceptions related to the quality of the unit. Unit assessors may chose to add specific
Table 3. Comparison of Student Outcomes All Sessions (2011-2013)

\begin{tabular}{lccccc}
\hline \multirow{2}{*}{ Student Grade } & 1 & 3 & 1 & 3 & 1 \\
& 2011 & 2011 & 2012 & 2012 & 2013 \\
\hline High & $4.6 \%$ & $3.5 \%$ & $6.9 \%$ & $9.7 \%$ & $9 \%$ \\
Distinction & & & & & \\
Distinction & $9.9 \%$ & $10.7 \%$ & $20.7 \%$ & $19.4 \%$ & $26 \%$ \\
Credit & $21.4 \%$ & $25 \%$ & $19 \%$ & $32.3 \%$ & $16 \%$ \\
Pass & $26.7 \%$ & $32.1 \%$ & $25 \%$ & $6.5 \%$ & $21.2 \%$ \\
Fail & $22.9 \%$ & $10.7 \%$ & $20.7 \%$ & $22.6 \%$ & $21 \%$ \\
Absent Fail & $14.5 \%$ & $21.4 \%$ & $7.8 \%$ & - & $5 \%$ \\
Total Students & $\mathbf{1 3 1}$ & $\mathbf{2 9}$ & $\mathbf{1 1 6}$ & $\mathbf{3 1}$ & $\mathbf{1 0 0}$ \\
\hline
\end{tabular}

Note: An Absent Fail grade is given to a student that has not engaged in the unit at all. (No assessments attempted).

questions in this survey, but in all cases, seven core questions must be included in the survey. Table 4 displays the results of the standard feedback questions for all sessions 2009-2013.

The session three results in 2010 and 2011 are the lowest of the results shown. As previously mentioned the use of the session one recorded lectures for these offerings meant that there was lack of interaction between students and the tutor in these sessions. This is clearly demonstrated by the results of the 'satisfaction with the way the unit was taught/delivered' and 'overall satisfaction' results for these sessions. In 2012 the session three tutor conducted four workshop Collaborate sessions with the students at the beginning of the session, and one week prior to each of the assessments due dates, the results for this session indicate this has gone a long way to improving the students perceptions.

Examination of all of the rest of the results in Table

Table 4. Unit Feedback Analysis (2009-2013)

\begin{tabular}{|c|c|c|c|c|c|c|c|c|}
\hline Standard Feedback Question & $\begin{array}{c}1 \\
2009 \\
\end{array}$ & $\begin{array}{c}1 \\
2010 \\
\end{array}$ & $\begin{array}{c}3 \\
2010 \\
\end{array}$ & $\begin{array}{c}1 \\
2011 \\
\end{array}$ & $\begin{array}{c}3 \\
2011 \\
\end{array}$ & $\begin{array}{c}1 \\
2012 \\
\end{array}$ & $\begin{array}{c}3 \\
2012 \\
\end{array}$ & $\begin{array}{c}1 \\
2013 \\
\end{array}$ \\
\hline $\begin{array}{l}\text { I am satisfied with the assessment tasks in this } \\
\text { unit }\end{array}$ & 3.61 & 3.80 & 3.67 & 4.09 & 3.62 & 4.30 & 4.20 & 4.40 \\
\hline $\begin{array}{l}\text { I am satisfied with the way this unit was } \\
\text { taught/delivered }\end{array}$ & 3.55 & 4.08 & 2.50 & 4.07 & 3.50 & 4.30 & 3.90 & 4.41 \\
\hline Overall, I am satisfied with this unit & 3.86 & 3.94 & 3.25 & 4.00 & 3.38 & 4.33 & 4.40 & 4.38 \\
\hline $\begin{array}{l}\text { Respect for cultural diversity was embedded in } \\
\text { this unit }\end{array}$ & 3.80 & 4.02 & 3.67 & 4.02 & 4.00 & 4.12 & 4.40 & 4.21 \\
\hline $\begin{array}{l}\text { The objectives and performance standards in this } \\
\text { unit were made clear }\end{array}$ & 3.84 & 4.08 & 3.83 & 4.14 & 3.62 & 4.33 & 4.50 & 4.56 \\
\hline The workload demands of the unit are about right & 3.45 & 3.63 & 3.67 & 4.11 & 4.00 & 4.12 & 4.20 & 4.23 \\
\hline $\begin{array}{l}\text { This unit helped me to develop some valuable } \\
\text { skills/attributes }\end{array}$ & 4.12 & 4.35 & 4.42 & 4.36 & 4.38 & 4.36 & 4.40 & 4.59 \\
\hline $\begin{array}{r}\text { Response Rate } \\
\end{array}$ & $44 \%$ & $37 \%$ & $43 \%$ & $33 \%$ & $28 \%$ & $33 \%$ & $31 \%$ & $39 \%$ \\
\hline
\end{tabular}

Note: Southern Cross University instituted a three session year in 2010.

Values shown are a calculated mean from a five point Lickert scale Strongly Disagree (1) to Strongly Agree (5). 
4 (ignoring the previous mentioned issues with session three 2010/2011 that was corrected in 2012) demonstrate a continuous improvement in students perceptions of the unit. For comparison purposes the university compares each unit's feedback results with the whole of university mean for the same session. The results for the Web Development I unit are better than the university mean in all seven standard questions. Table 5 following displays this comparison for session one 2013.

Table 5. Comparison of Results Web Development 1 to University Mean Session 12013

\begin{tabular}{lcc}
\hline \multicolumn{1}{c}{ Standard Feedback Question } & $\begin{array}{c}\text { Web Dev } \\
\text { Unit }\end{array}$ & $\begin{array}{c}\text { Uni } \\
\text { Mean }\end{array}$ \\
\hline $\begin{array}{l}\text { I am satisfied with the assessment } \\
\text { tasks in this unit }\end{array}$ & 4.40 & 3.86 \\
\hline $\begin{array}{l}\text { I am satisfied with the way this unit } \\
\text { was taught/delivered }\end{array}$ & 4.41 & 3.84 \\
$\begin{array}{l}\text { Overall, I am satisfied with this unit } \\
\begin{array}{l}\text { Respect for cultural diversity was } \\
\text { embedded in this unit }\end{array}\end{array}$ & 4.38 & 3.91 \\
$\begin{array}{l}\text { The objectives and performance } \\
\text { standards in this unit were made clear }\end{array}$ & 4.56 & 4.15 \\
$\begin{array}{l}\text { The workload demands of the unit } \\
\text { are about right }\end{array}$ & 4.23 & 3.98 \\
$\begin{array}{l}\text { This unit helped me to develop some } \\
\text { valuable skills/attributes }\end{array}$ & 4.59 & 4.09 \\
\hline
\end{tabular}

\subsection{Anonymous Student Feedback}

Perhaps the final evidence of improvement in the unit should come from anonymous student feedback. These comments are drawn from the qualitative section of the 2012 and 2013 Web Development I "Student Feedback on Learning and Teaching” as responses to the item, "Here is your opportunity to tell us how to improve this unit:”

- "Camtasias were very helpful and the chapter breakdown in unit documentation was great”

- "A few more Camtasias - maybe one for each topic would be good for long distance students"

- "Nothing. The unit is very well structured. The way the assessment task flow together makes completing the unit less stressful. I found the Camtasias were really good for getting my projects started."

- "Nothing needs to be done, every student I have spoken with about this subject felt they all had a solid understanding of the topics provided and if they didn't understand were not afraid to ask, unlike some other subjects."

- "Excellent study materials very clear lectures that weren't too much to take in. Reliable and timely responses and marking."

- "I felt overwhelmed coming into this course, but settled into it within a few weeks. The teaching methods are brilliant, as we were encouraged to learn at our own pace, but always had a staff member ready to assist with any queries."

- "I found this unit's material thoroughly comprehensive. Between the textbook, the online lectures, the study guide and the Camtasias, there was more than enough information provided. Very comprehensive. I haven't seen Camtasias before, they are awesome and really summed up information quite quickly. Was great to actually watch how it is done and it was a quick process. Very happy. Can't think of anything that could improve this unit. Very well handled."

- "The unit was a great unit to undertake. I do feel that some more JavaScript should have been covered even though I do not know what you would take out to accommodate it. It was a brief look at JavaScript but it could be expanded a little more I think."

\section{Awards}

The continuous improvements to the Web Development I unit have been recognized by colleagues in the Southern Cross Business School, and by the university as a whole. In 2011 as part of the 'Converged Delivery Project $^{23}$, the Web Development I unit was selected as an "Teaching Exemplar" this is described by the Division of Teaching and Learning as:

"The teaching exemplars represent a range of creative and inspiring approaches used at SCU to support student learning. Case studies have been selected as exemplars based on their ability to:

- engage learners or support learner engagement

- demonstrate capacity to be transferred to other teaching environments

- be easily implemented, and

- demonstrate sustainability over a number of years ${ }^{30}$."

In 2012 the unit was again recognized by the university when the unit assessor received a Vice 
Chancellors Award "For sustained provision of teaching practices including innovative and flexible web-based learning resources that inspire and motivate students from diverse backgrounds in introductory web development ${ }^{31, \text {, }}$

\section{Reflective teaching practise}

At the end of each session, a unit report is prepared for the course coordinator. This process provides the opportunity to reflect on what went well and what needs to be addressed in a unit and it is this reflection that has driven the continuous improvement to the Web Development unit.

Additionally, annually since 2010, Southern Cross University's Division of Teaching and Learning holds a "Festival of Teaching" where the results of projects undertaken by the division are disseminated to staff. This is an excellent opportunity to share information between colleagues in your own discipline and colleagues in different disciplines what is working in the teaching space. The authors have been involved with many of the projects over the last five years including:

- First Year @SCU Project

- Converged Delivery Project ${ }^{23}$

- Excellence in Assessment Project ${ }^{24}$

- eMarking Project

Presenting your accomplishments and more importantly hearing other presentations as part of "Festival of Learning" are extremely beneficial to reflective teaching practice.

Finally just to note, the process of continuous improvement continues as tweaking the units learning materials, technologies in use and assessment strategy is ongoing. There is always something that can be improved.

\section{Conclusion}

In this paper a case study of the Web Development I teaching practices was detailed. The unit design and student cohort over a five-year period (2009-2013) was examined in depth. The introduction and usage of technologies enabling converged delivery, assessment strategies including design, rubrics and a proactive approach were also discussed. Finally, the student learning outcomes and perceptions were examined, showing that the synergy of all of the practices adopted over this period has demonstrated a significant improvement.

\section{Acknowledgements}

The authors would like to thank all the tutors onshore and overseas involved in teaching the Web Development unit (2009-2013). Running a multicampus, multi-location unit is after all a team effort.

\section{References}

1. J.B. Biggs, Enhancing teaching through constructive alignment, Higher Education 32(3) (1996) 347-364.

2. J.B Biggs, Teaching for Quality Learning at University 2nd edn. (Society for Research into Higher Education and Open University Press, Berkshire, UK, 2003)

3. D. Rowntree, Preparing Materials for Open, Distance and Flexible Learning, (Open and Distance Learning Series, London, UK, 1994).

4. L. Dunn et al., The Student Assessment Handbook, (RoutledgeFalmer, London and New York, 2004).

5. S. Toohey, Designing Courses for Higher Education, (Society for Research into Higher Education and Open University Press, Berkshire, UK, 1999).

6. D. Lake, Reducing isolation for distance students: An online initiative, The Proceedings of the 8th Annual Teaching Learning Forum, (University of Western Australia, Perth, Australia, 1999) 210-214.

7. R. Mason, Using Communications Media in Open and Flexible Learning, (Open and Distance Learning Series, London, UK, 1994).

8. O. Peters, Some observations on dropping out in distance education, Distance Education 13(2) (1992) 234-269.

9. P.H. Rogers, Student retention and attrition in college, in Handbook of developmental education, R.M. Hashway, ed. (Praeger, NY, USA, 1990) 305-327.

10. H. Hipp, Women studying at a distance: what do they need to succeed?, Open Learning, 20(1) (1997) 22-30.

11. E. Cuskell, P. Danaher, and K. Purnell, Just which technologies do distance students really want? Results of focus group research, The Proceedings of the 13th Biennial Forum of the Open and Distance Learning Association of Australia, (University of Tasmania, Launceston, Australia, 1997) 88-93.

12. M. Oliver and K. Trigwell, Can 'Blended Learning' Be Redeemed?” E-Learning, 2(1) (2005) 17-26.

13. W. Kim, Towards a definition and methodology for blended learning", in Blended Learning F.J. and F.L. Wang eds. (Pearson Prentice Hall, Singapore, 2006) 1-8.

14. C. Bonk, K.J. Kim, and T Zeng, "Future directions of blended learning in higher education and workplace settings", in The Handbook of Blended Learning C.J. Bonk and C.R. Graham eds, (Pfeiffer, San Francisco, USA, 2006) 550-567.

15. N. Vaughan and M. Power, "BOLD Blended Online Learning Design: Shaken not Stirred, Canadian Institute of 
Distance Education PowerPoint presentation, (2010) Online available at, http://cider.athabascau.ca/

CIDERSessions/mpower/CIDER-FINAL.pdf (accessed Jul. 17, 2012)

16. J. Bird, Mapping flexibilities, 27th Higher Education Research and Development Society of Australasia Conference Proceedings. (Sarawak, Malaysia 2004) 6271.

17. M. Tulloch et al., Towards a Leading Edge Learning Environment at CSU: Maximising responsiveness and flexibility through blended and convergent learning approaches, (Central Queensland University, Australia, 2005) Online available at "http://www.csu.edu.au/ _data/assets/word_doc/0004/53608/CELT_Leading_Edg e.doc” (accessed Jul. 17, 2012).

18. J.A. Snart, Hybrid learning: the perils and promise of blending online and face-to-face instruction in higher education, (Praeger, Santa Barbara, USA, 2010)

19. J. Macdonald, Blended learning and online tutoring: planning learner support and activities, (Gower Publishing, Burlington, USA, 2006).

20. Commonwealth of Australia, Australian Flexible Learning Framework, (2010) Online available at http://www.flexiblelearning.net.au/ (accessed Jul 17, 2012)

21. Australian National Training Authority, Australian Flexible Learning Framework for the National Vocational Education and Training System 2000-2004, (2005) Online available at http://www.dest.gov.au/sectors/ training_skills/publications_resources/profiles/anta/profile /australian_national_learning_framework_2000_2004.htm (accessed Jul. 17, 2012).

22. New Directions for Delivery Action Group, New Directions for Delivery at Southern Cross University: Final Report, (Southern Cross University. Lismore, Australia, 2007).

23. J.A. Taylor and D. Newton, Converged Delivery at SCU An Investigative Project: Final Report, (Southern Cross University, Lismore, Australia, 2011).

24. J.A. Taylor and C. Morgan, Excellence in Assessment Project Southern Cross University Final Report, (Southern Cross University, Lismore, Australia, 2011).

25. W.J. Smart, Distance Education a Proactive Approach, Proceedings of the 5th Online Distance Learning Conference, (Brisbane, Australia, 2005).

26. Macquarie University Teaching and Learning Centre, Assessment Toolkit Resources, (2008) Online available at http://staff.mq.edu.au/public/download/?id=40247” (accessed Jul.16, 2012).m

27. J. Orrell, A Generic Learning Rubric, (Flinders University, Adelaide, Australia, 2003).

28. D. Stevens and A. Levi, Introduction to Rubrics: An Assessment Tool to Save Grading Time, Convey Effective Feedback and Promote Student Learning, (Stylus Publishing, Sterling, USA, 2005).

29. M. Hickey, Assessment Rubrics for Music Composition, Music Educators Journal, 84(4) (1999) 36-42.
30. Southern Cross University, Teaching Exemplars, (Division of Teaching and Learning, Southern Cross University, Oct. 2011) Online available at http://scu.edu.au/teachinglearning/tlc/exemplars/index.ph p/17 (accessed Dec 3, 2013).

31. Southern Cross University, 2012 Southern Cross University Annual Report, (2012) Online available at http://scu.edu.au/docs/annual_report/ (accessed Dec. 3, 2013). 